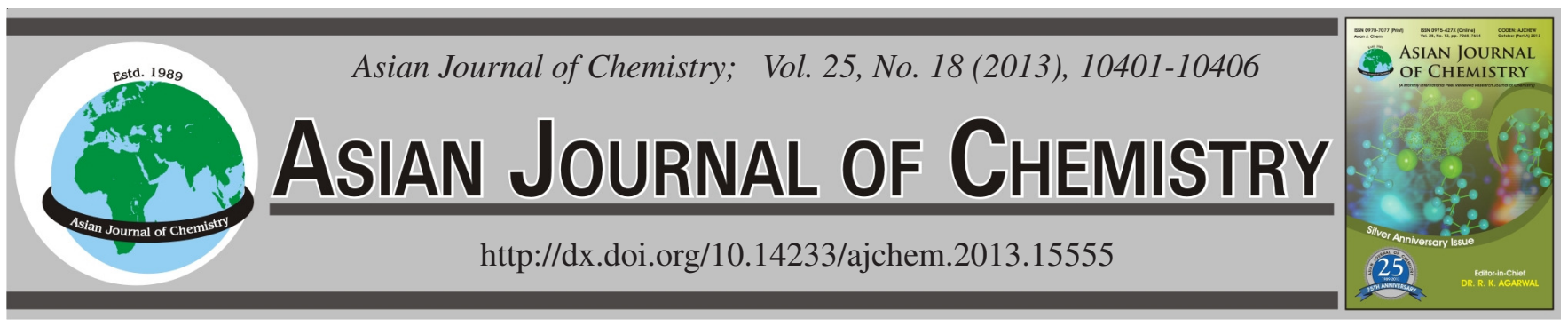

\title{
Microwave-Assisted Synthesis, Characterization and Aggregation Properties of Phthalocyanines Containing Azo Dye
}

\author{
CiHan Kantar
}

Department of Chemistry, Science and Literature Faculty, Recep Tayyip Erdogan University, 53100 Rize, Turkey

Corresponding author: E-mail: cihankantar@hotmail.com

\section{INTRODUCTION}

Phthalocyanines have considerable industrial importance for use in dyes, paints, colour for metal surfaces, fabrics and plastics. In recent years, various phthalocyanine complexes have been synthesized, characterized and investigated in terms of their properties. Various investigations have concerned the potential utility of metallophthalocyanines (MPcs) as solar cell functional materials ${ }^{1}$, sensing elements in chemical sensors ${ }^{1,2}$, optical storage vehicles and nonlinear optical limiting devices ${ }^{1-3}$, photoconducting agents in photocopying machines ${ }^{1-4}$, electrocatalysts $^{1-5}$ and photodynamic reagents for cancer therapy and for other medical applications ${ }^{1-10}$.

It is well known that microwave irradiation can accelerate a number of chemical processes and, in particular, the reaction time and energy input are supposed to be mostly reduced in the reactions that are run for a long time at high temperatures under conventional conditions ${ }^{11}$. Microwave processing has attracted potential as an alternative to classical thermal processing because of the inherent advantage of microwave heating, which is selective, direct, rapid, internal and contro1lable $\mathrm{e}^{12-14}$. The synthesis of phthalocyanines under microwave irradiation reduces reaction times and enhances yields in comparison with classical method ${ }^{15}$. We have previously reported about microwave assisted synthesis of phthalocyanines containing substituent (e.g. phenoxy ${ }^{15}$, triazole ${ }^{16}$, oxa $\mathrm{aza}^{17}$ and $\left.\mathrm{azo}^{18}\right)$.
Since their extended $\pi$-systems, macrocyclic phthalocyanine compounds exhibit an high aggregation tendency forming dimeric and oligomeric species and thus cause a decrease in light absorptions. On the other hand, the formation of phthalocyanine aggregates is useful in materials applications where the self-assembly of phthalocyanine cores in close proximity is beneficial.

So far there has been no report about aggregation properties of phthalocyanines containing azo dyes with halogen atom as substituent. In this study, novel phthalocyanine-azobenzene dyes were synthesized by microwave-assisted method and the effect of the concentration on the aggregation properties of zinc complexes (1a, 2a and 3a) was studied in solutions.

\section{EXPERIMENTAL}

4-Nitro-1,2-dicyanobenzene and 4,5-dichloro-1,2-dicyanobenzene were prepared by a reported procedure ${ }^{19,20}$. 4-Iodoaniline and phenol were purchased from Merck Chemical Company. FTIR spectra were recorded Perkin-Elmer Spectrum 100 Infrared Spectrometer as $\mathrm{KBr}$ pellets. UV/visible spectra were recorded on Mattson UNICAM UV/visible spectrometer. ${ }^{1} \mathrm{H}$ NMR and ${ }^{13} \mathrm{C}$ NMR studies were done on Brucker AC-200 FT-200 FTNMR. Elemental analyses were performed by the Instrumental Analyses Laboratory of the TÜBITAK Gebze Research Center. Mass spectra were performed on Thermo TSQ Quantum acces max. Microwave-assisted syntheses were carried out using monomode CEM-Discover microwave apparatus. 
4-Iodo phenyl azo 4'-hydroxy phenyl (I): 4-Iodoaniline $(2190 \mathrm{mg}, 10 \mathrm{mmol})$ was dissolved in pure water $(15 \mathrm{~mL})$ and $\mathrm{HCl}(3 \mathrm{~mL}, 30 \%)$. Then the solution of sodium nitrite $(690$ $\mathrm{mg}, 10 \mathrm{mmol}$ ) was added dropwise to this solution at $0-5^{\circ} \mathrm{C}$. Temperature was kept at $0-5^{\circ} \mathrm{C}$ during addition. A solution of phenol (940 mg, $10 \mathrm{mmol})$ in $\mathrm{NaOH}$ solution $(50 \mathrm{~mL}, 10 \%)$ was added with efficiently stirring to this diazonium solution. Dilute $\mathrm{HCl}$ solution was added until mixture was neutral. The formed solid product was separated by filtration, purified by crystallization from dry ethanol. Yield: $1940 \mathrm{mg}$ (60\%.); m.p. $157-158{ }^{\circ} \mathrm{C}$.

This compound is soluble ethanol and dimethyl sulphoxide. IR $v_{\max } / \mathrm{cm}^{-1} 3190(\mathrm{OH}), 3077(\mathrm{Ar}-\mathrm{CH}), 1591(\mathrm{C}=\mathrm{C}), 1585$, $1473(\mathrm{~N}=\mathrm{N}), 1390,1238,1217,1141,1098,1052,1002,829$. ${ }^{1} \mathrm{H}$ NMR (DMSO- $\left.d_{6}\right) \delta$, ppm: $9.44(1 \mathrm{H}, \mathrm{s}, \mathrm{OH}), 7.97-6.8(8 \mathrm{H}$, $\mathrm{m}, \mathrm{Ar}-\mathrm{CH}) .{ }^{13} \mathrm{C}$ NMR (DMSO- $\left.d_{6}\right) \delta$, ppm: 156.62, 154.31, $153.47,135.12,131.31,130.61,129.87,127.67 . \mathrm{MS}: \mathrm{m} / \mathrm{z}$ $325.13\left(\mathrm{M}^{+}\right), 324.11(\mathrm{M})$.

4-(4-Iodo phenylazo 4'-phenoxy)-1,2-dicyanobenzene (1): Compound (I) (1000 mg $3.08 \mathrm{mmol})$ and 4-nitro-1,2dicyanobenzene $(533 \mathrm{mg}, 3.08 \mathrm{mmol})$ were dissolved in dry DMSO $(20 \mathrm{~mL})$ under nitrogen. After stirring for $0.5 \mathrm{~h}$, finely ground anhydrous $\mathrm{K}_{2} \mathrm{CO}_{3}(630 \mathrm{mg}, 4.62 \mathrm{mmol})$ was added portion wise over $2 \mathrm{~h}$ with efficient stirring. The reaction mixture was stirred under $\mathrm{N}_{2}$ at room temperature for $72 \mathrm{~h}$. The reaction mixture was poured in water bath and $\mathrm{HCl}$ solution was added to eliminate base trace. Formed solid material was filtered off and washed with water until the filtrate became neutral. The crude product was purified by recrystallization from dry ethanol. Yield $1200 \mathrm{mg}(85 \%)$; m.p. $164-165^{\circ} \mathrm{C}$.IR $v_{\max } / \mathrm{cm}^{-1} 3077(\mathrm{Ar}-\mathrm{CH}), 2232(\mathrm{CN}), 1586,1562,1483(\mathrm{~N}=\mathrm{N})$, 1409, 1279, 1248, 1205, 1140, 1005, 843. ' H NMR (DMSO$\left.d_{6}\right) \delta$, ppm: 8.06-8.04 (2H, d, Ar-CH), 7.92-7.90 (2H, d, Ar-CH), 7.80-78 (1H, d, Ar-CH), 7.69-7.66 (2H, d, Ar-CH), 7.40-7.33 (1H, m, Ar-CH), 7.28 (1H, s, Ar-CH), 7.25-7.22 $(2 \mathrm{H}, \mathrm{d}, \mathrm{Ar}-\mathrm{CH}) .{ }^{13} \mathrm{C}$ NMR (DMSO- $\left.d_{6}\right) \delta$, ppm: 160.98, 155.96, $151.73,150.15,138.48,135.55,125.38,124.52,122.14$, 121.94, 120.89, 117.93, 115.51(CN), 115.04, 109.71, 98.19. MS: $m / z 451.05\left(\mathrm{M}^{+}\right), 450.23(\mathrm{M})$.

4-(4-Iodo phenylazo 4'-phenoxy)-5-chloro-1,2dicyanobenzene (2) and 4,5-bis(4-iodo phenylazo-4'phenoxy)-1,2-dicyanobenzene (3): Compound (I) (1000 mg $3.08 \mathrm{mmol}$ ) and 4,5 dichloro-1,2-dicyanobenzene $(300 \mathrm{mg}$, $1.52 \mathrm{mmol}$ ) were dissolved in dry DMSO (20 mL) under nitrogen. After stirring for $0.5 \mathrm{~h}$, finely ground anhydrous $\mathrm{K}_{2} \mathrm{CO}_{3}(638 \mathrm{mg}, 4.62 \mathrm{mmol})$ was added portion wise over $2 \mathrm{~h}$ with efficient stirring. The reaction mixture was stirred under $\mathrm{N}_{2}$ at room temperature for $72 \mathrm{~h}$. The reaction mixture was poured in water bath and $\mathrm{HCl}$ solution was added to eliminate base trace. Formed solid material was filtered off and washed with water until the filtrate became neutral. The crude product was purified by column chromatography on silica gel using chloroform/methanol (100:1) mixture as eluent. As the first fraction $660 \mathrm{mg}(55 \%)$ of compound (2) and second fraction $220 \mathrm{mg}$ (18\%) of compound (3) were obtained. Compound (2): Yield $660 \mathrm{mg}(55 \%)$; m.p. $226-227{ }^{\circ} \mathrm{C}$. IR $\left(\mathrm{V}_{\max }, \mathrm{cm}^{-1}\right)$ : 3096, 3039 (Ar-CH), $2234(\mathrm{CN}), 1578,1557,1484(\mathrm{~N}=\mathrm{N})$, 1382, 1273, 1201, 1137, 1097, 1004, 866, 836. ${ }^{1} \mathrm{H}$ NMR $\left(\mathrm{DMSO}-d_{6}\right) \delta$, ppm: 8.08-8.06 (2H, d, Ar-CH), 7.94-7.89 (2H, t, Ar-CH), 7.70-7.67 (2H, d, Ar-CH), 7.28 (1H, s, Ar-CH), 7.24-7.25 (2H, d, Ar-CH), $7.22(1 \mathrm{H}, \mathrm{s}, \mathrm{Ar}-\mathrm{CH}) .{ }^{13} \mathrm{C}$ NMR $\left(\mathrm{DMSO}-d_{6}\right) \delta$, ppm: 157.13, 155.69, 151.71, 150.31, 138.49, $135.78,134.96,130.36,125.49,124.55,121.61,120.53$, $115.69(\mathrm{CN}), 114.20,110.71,98.30 . \mathrm{MS}: \mathrm{m} / z 485.05\left(\mathrm{M}^{+}\right)$, $484.67(\mathrm{M})$.

Compound (3): Yield $220 \mathrm{mg}$ (18\%); m.p. 192-193 ${ }^{\circ} \mathrm{C}$. IR $v_{\max } / \mathrm{cm}^{-1}$ 3096, 3035 (Ar-CH), $2234(\mathrm{CN}), 1578,1565$, 1483, 1473 (N=N), 1382, 1274, 1255, 1203, 1138, 1098, 1003, 839. ${ }^{1} \mathrm{H}$ NMR (DMSO- $\left.d_{6}\right) \delta$, ppm: 8.08-8.06 (4H, d, Ar-CH), 7.94-7.89 (4H, t, Ar-CH), 7.70-7.66 (4H, d, Ar-CH), 7.28 (1H, s, Ar-CH), 7.24-7.23 (4H, d, Ar-CH), $7.19(1 \mathrm{H}, \mathrm{s}, \mathrm{Ar}-\mathrm{CH}) .{ }^{13} \mathrm{C}$ NMR (DMSO- $d_{6}$ ) $\delta$, ppm: 157.13, 155.69, 151.71, 150.31, $138.49,138.26,135.78,130.37,125.49,125.15,124.55$, 124.23, 121.61, 120.52, $115.89(\mathrm{CN}), 115.68,114.19,114.12$, 110.70, 98.30. MS: $m / z 777.95\left(\mathbf{M}^{+}\right), 776.94(\mathrm{M})$.

Microwave-assisted synthesis of zinc phthalocyanine (1a): Compound 1 (200 mg, 0,44 mmol), $\mathrm{Zn}\left(\mathrm{CH}_{3} \mathrm{COO}\right)_{2}(0.11$ mmol), DMF (5 mL) and 2-3 drops DBU (1,8-diazabicyclo [5.4.0] undec-7-ene) were charged together into round bottomed flask. The reaction flask was irradiated by a microwave apparatus at $600 \mathrm{~W}$ for $20 \mathrm{~min}$. After cooling to room temperature, the reaction mixture was treated with water to precipitate the product which was filtered off. The green product was washed with hot ethanol and ethyl acetate. Synthesized phthalocyanine was soluble in DMF and DMSO. Zinc phthalocyanine (1a); Yield $192 \mathrm{mg}(92 \%)$ m.p. $>200{ }^{\circ} \mathrm{C}$. FTIR $\left(v_{\max }, \mathrm{cm}^{-1}\right): 3060$ $(\mathrm{Ar}-\mathrm{CH}), 1602(\mathrm{C}=\mathrm{C}), 1504,1469(\mathrm{~N}=\mathrm{N}), 1393,1222,1226$, 1088, 1043, 829. Anal. Calcd. For $\mathrm{C}_{80} \mathrm{H}_{44} \mathrm{~N}_{16} \mathrm{O}_{4} \mathrm{I} 4 \mathrm{Zn}$ : C, 67.54; H, 4.25; N, 13.13. Found: C, 67.50; H, 4.19; N, 13.09. UVvisible (DMF): $\lambda_{\max } / \mathrm{nm} 268,353,614,682$.

Microwave-assisted synthesis of zinc phthalocyanine (2a): Compound 2 (200 mg, 0,41 mmol), $\mathrm{Zn}\left(\mathrm{CH}_{3} \mathrm{COO}\right)_{2}(0.11$ mmol), DMAE ( $5 \mathrm{~mL}$ ) and 2-3 drops DBU (1,8-diazabicyclo[5.4.0] undec-7-ene) were charged together into round bottomed flask. The reaction flask was irradiated by a microwave apparatus at $600 \mathrm{~W}$ for $20 \mathrm{~min}$. After cooling to room temperature, the reaction mixture was treated with alcohol to precipitate the product which was filtered off. The crude product was purified by column chromatography on silica gel using chloroform/methanol (40:1) mixture as eluent. Synthesized phthalocyanine was soluble in chloroform. Zinc phthalocyanine (2a); Yield $192 \mathrm{mg}(92 \%)$ m.p. $>200{ }^{\circ} \mathrm{C}$. FTIR $\left(v_{\max }, \mathrm{cm}^{-1}\right): 3100$ $(\mathrm{Ar}-\mathrm{CH}), 1645(\mathrm{C}=\mathrm{C}), 1589,1490(\mathrm{~N}=\mathrm{N}), 1430,1389,1321$, 1241, 1201, 1094, 990, 893, 744, 687. Anal. Calcd. For $\mathrm{C}_{80} \mathrm{H}_{40} \mathrm{~N}_{16} \mathrm{O}_{4} \mathrm{I}_{4} \mathrm{Cl}_{4} \mathrm{Zn}: \mathrm{C}, 67.54 ; \mathrm{H}, 4.25 ; \mathrm{N}, 13.13$. Found: $\mathrm{C}$, 67.50; H, 4.19; N, 13.09. UV-visible $\left(\mathrm{CHCl}_{3}\right): \lambda_{\max }(\mathrm{nm}): 241$, $343,615,681$.

Microwave-assisted synthesis of zinc phthalocyanine (3a): Compound 3 (200 mg, $0.25 \mathrm{mmol}), \mathrm{Zn}\left(\mathrm{CH}_{3} \mathrm{COO}\right)_{2}$ (0.07 mmol), $n$-pentanol $(5 \mathrm{~mL})$ and $2-3$ drops DBU $(1,8-$ diazabicyclo[5.4.0] undec-7-ene) were charged together into round bottomed flask. The reaction flask was irradiated by a microwave apparatus at $600 \mathrm{~W}$ for $20 \mathrm{~min}$. After cooling to room temperature, the reaction mixture was treated with alcohol to precipitate the product which was filtered off. The crude product was purified by column chromatography on silica gel using chloroform/methanol (40:1) mixture as eluent. Synthesized phthalocyanine was soluble in chloroform. Zinc 
phthalocyanine (3a); Yield $192 \mathrm{mg}(92 \%)$ m.p.>200 ${ }^{\circ} \mathrm{C}$. FTIR $\left(v_{\max }, \mathrm{cm}^{-1}\right): 3064(\mathrm{Ar}-\mathrm{CH}), 1651(\mathrm{C}=\mathrm{C}), 1587,1491(\mathrm{~N}=\mathrm{N})$, 1388, 1240, 1226, 1197, 1139, 1095, 992, 839, 742. Anal. Calcd. For $\mathrm{C}_{128} \mathrm{H}_{72} \mathrm{~N}_{24} \mathrm{O}_{8} \mathrm{I}_{8} \mathrm{Zn}$ : C, 67.54; H, 4.25; N, 13.13 . Found: C, 67.50; H, 4.19; N, 13.09. UV-visible $\left(\mathrm{CHCl}_{3}\right): \lambda_{\max }$ (nm) 243, 349, 614, 681 .

\section{RESULTS AND DISCUSSION}

Synthesis and characterization: The synthetic route of azo dye and the newly phthalocyanines ( $\mathrm{Zn}$ ) substituted with azo compound is given Figs. 1 and 2.4-Nitro-1,2-dicyanobenzene and 4,5-Dichloro-1,2-dicyanobenzene are used to prepare mono and di substituted phthalonitrile derivatives through base-catalyzed nucleophilic aromatic displacement ${ }^{19,20}$.

In order to obtain phthalocyanines substituted with azo compound, firstly 4-iodo phenyl azo 4'-hydroxy phenyl (I) was prepared by the treatment of 4-iodoaniline with phenol. All spectroscopic data of compound (I) show good agreement with the values reported in the literature ${ }^{21}$.

The synthesis of phthalonitrile compounds was the most important step in these reaction sequences. For this purpose, compounds $(\mathbf{1}, \mathbf{2}$ and $\mathbf{3})$ were synthesized by treating compound (I) with 4-nitro-1,2-dicyanobenzene and 4,5-dichloro-1,2dicyanobenzene, respectively, in DMSO using $\mathrm{K}_{2} \mathrm{CO}_{3}$ as the base for nucleophilic aromatic substitution at room temperature for $72 \mathrm{~h}$. Purification of compounds (1, 2 and $\mathbf{3}$ ) was carried out by recrystallization (for $\mathbf{1}$ ) and column chromatographic method (for $\mathbf{2}$ and $\mathbf{3}$ ).

At the last step, zinc phthalocyanines were synthesized using microwave irradiation from the corresponding phthalonitrile compounds and metal salts in amyl alcohol/DMF or DMAE mixture for $20 \mathrm{~min}$. Purification of phthalocyanine compounds<smiles>Nc1ccc(I)cc1</smiles>

$p$-Iodo aniline<smiles>C[PbH]</smiles><smiles>N#Cc1ccc([N+](=O)[O-])cc1C#N</smiles><smiles>Oc1ccc(N=Nc2ccc(I)cc2)cc1</smiles><smiles>CC#CC</smiles>

4-Nitro-1,2-dicyano phthalonitrile

\section{I}<smiles>N#Cc1ccc(Oc2ccc(N=Nc3ccc(I)cc3)cc2)cc1C#N</smiles><smiles>CC#CCCCCC#N</smiles>

i) $\mathrm{NaNO}_{2} / \mathrm{HCl}, 0-5{ }^{\circ} \mathrm{C}$

ii) $\mathrm{K}_{2} \mathrm{CO}_{3}$, DMSO, $60{ }^{\circ} \mathrm{C}, 3$ days

iii) Metal salt, DBU, DMF, $600 \mathrm{Watt}, 20 \mathrm{~min}$

(1a)

Fig. 1. Synthesis of compound (1) and phthalocyanine (1a) 

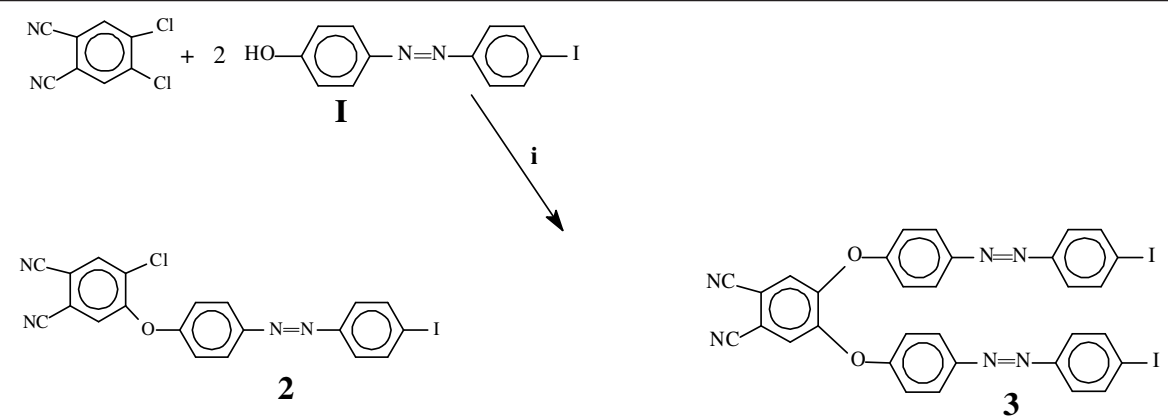

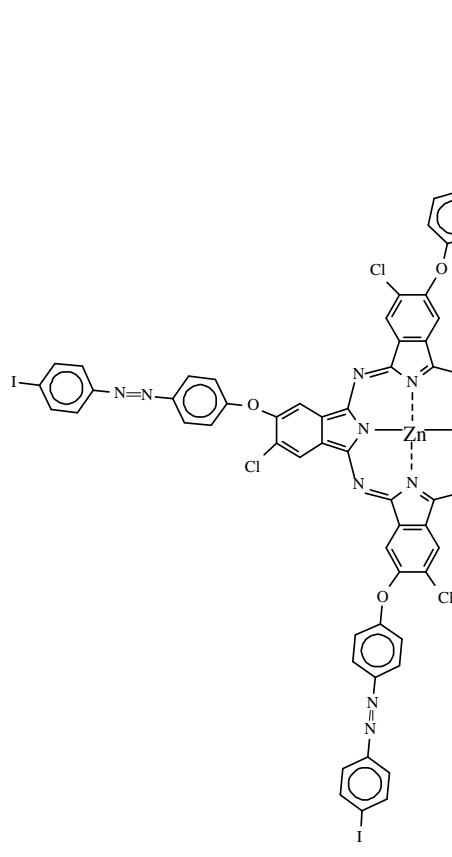

(2a) i) $\mathrm{K}_{2} \mathrm{CO}_{3}$, DMSO, $60{ }^{\circ} \mathrm{C}, 3$ days

ii) Metal salt, DBU, DMF, 600 Watt, $20 \mathrm{~min}$

iii) Metal salt, DBU, pentanol, 600 Watt, 20 min

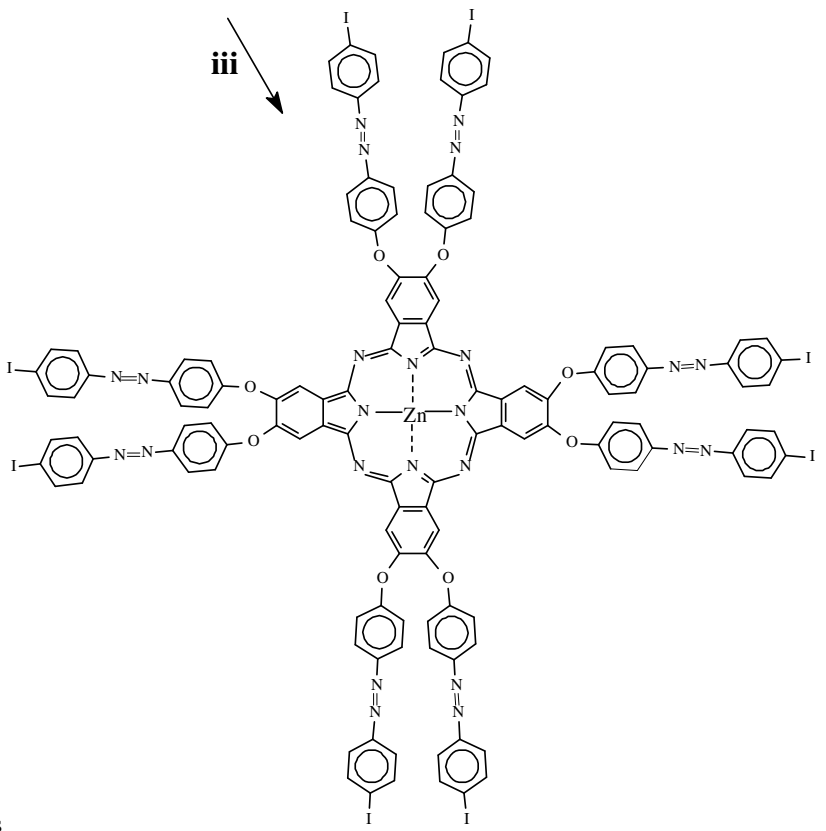

(3a)

Fig. 2. Synthesis of compounds $(\mathbf{2}, \mathbf{3})$ and phthalocyanines (2a and $\mathbf{3 a})$

(1a, 2a and 3a) was carried out extraction with hot ethanol (for 1a) and column chromatographic method (for 2a and 3a). All phthalocyanines were soluble in DMF and DMSO. Characterization of the products involved a combination of method including IR, elemental analysis, UV-visible spectroscopy, ${ }^{1} \mathrm{H}$ $\mathrm{NMR},{ }^{13} \mathrm{C}$ NMR and mass spectroscopy. Elemental analysis results of the starting materials and the phthalocyanine compounds show good agreement with the calculated values.

Spectral investigations of the new synthesized ligand and phthalocyanines show good agreement with proposed structures. FTIR spectrum of compound (I) shows broad $\mathrm{OH}$ band at $3190 \mathrm{~cm}^{-1}$ and azo group peak $(\mathrm{N}=\mathrm{N})$ at $1473 \mathrm{~cm}^{-1}$. For the ${ }^{1} \mathrm{H}$ NMR spectrum of compound (I), hydroxyl proton showed a singlet peak at $9.44 \mathrm{ppm}$.

The formation of compound (1) was clearly indicated by the disappearance of the $\mathrm{OH}$ band at $3190 \mathrm{~cm}^{-1}$ and appearance of the CN band at $2232 \mathrm{~cm}^{-1}$ in its FTIR spectrum. The FTIR spectra of the phthalocyanine (1a) clearly indicate the cyclotetramerization of the phthalonitrile derivatives with the disappearance of the $\mathrm{CN}$ peak at $2232 \mathrm{~cm}^{-1}$.

The reaction of compound $\mathbf{I}$ with 4,5-dichloro phthalonitrile results in providing two compounds ( 2 and $\mathbf{3}$ ). Compounds ( 2 and 3) have one and two azo dyes as subtituent, respectively. These compounds seperated by column chromatographic method. According to this, at 4,5-dichloro phthalonitrile displacement of one or two chloro atom might be a consequence of steric hindrance of the bulky groups, the acidic capacities of the displacement groups and the strength of the bases used in these reactions ${ }^{22-25}$.

The formation of compound (2) was clearly indicated by the disappearance of the $\mathrm{OH}$ band at $3190 \mathrm{~cm}^{-1}$ and appearance of the CN band at $2234 \mathrm{~cm}^{-1}$ in its FTIR spectrum. The FTIR spectra of the phthalocyanine (2a) clearly indicate the cyclotetramerization of the phthalonitrile derivatives with the disappearance of the $\mathrm{CN}$ peak at $2234 \mathrm{~cm}^{-1}$. The formation of compound (3) was clearly indicated by the disappearance of the $\mathrm{OH}$ band at $3190 \mathrm{~cm}^{-1}$ and appearance of the $\mathrm{CN}$ band at $2234 \mathrm{~cm}^{-1}$ in its FTIR spectrum. The FTIR spectra of the phthalocyanine (3a) clearly indicate the cyclotetramerization of the phthalonitrile derivatives with the disappearance of the $\mathrm{CN}$ peak at $2234 \mathrm{~cm}^{-1}$.

The formation of compound (1) was clearly indicated by the disappearance of the $\mathrm{OH}$ peak at $9.44 \mathrm{ppm}$ and appearance of the extra aromatic peaks at 8.06-8.22 ppm in its ${ }^{1} \mathrm{H}$ NMR spectrum. The ${ }^{13} \mathrm{C}$ NMR spectrum of compound (1) indicated the presence of nitrile carbon atoms at $115.51 \mathrm{ppm}$. The formation of compound (2) was clearly indicated by the disappearance of the $\mathrm{OH}$ peak at $9.44 \mathrm{ppm}$ and appearance of 
the extra aromatic peaks at 8.08-7.22 ppm in its ${ }^{1} \mathrm{H}$ NMR spectrum. The ${ }^{13} \mathrm{C}$ NMR spectrum of compound (2) indicated the presence of nitrile carbon atoms at $115.69 \mathrm{ppm}$. The formation of compound (3) was clearly indicated by the disappearance of the $\mathrm{OH}$ peak at $9.44 \mathrm{ppm}$ and appearance of the extra aromatic peaks at 8.08-7.19 ppm in its ${ }^{1} \mathrm{H}$ NMR spectrum. The ${ }^{13} \mathrm{C}$ NMR spectrum of compound (3) indicated the presence of nitrile carbon atoms at $115.89 \mathrm{ppm}$.

${ }^{1} \mathrm{H}$ NMR and ${ }^{13} \mathrm{C}$ NMR spectra of phthalocyanines is somewhat broader than the corresponding signals in the dinitrile derivative. It is probable that the broadening is due to chemical exchange caused by aggregation-disaggregation equilibria and the fact that the phthalocyanine derivative obtained in these reactions is a mixture of positional isomers which are expected to show chemical shifts that differ slightly from each other ${ }^{24}$.

High resolution mass spectra (ESI) of compounds I, 1, 2 and $\mathbf{3}$ provided a definitive proof for their characterization. Ionization took place in the methanol solution. Peaks corresponding to the molecular ions of compounds I, 1, 2 and $\mathbf{3}$ were detected as expected. Mass spectrum measurements confirmed unambiguously the molecular mass of compounds (I) $(\mathrm{m} / \mathrm{z}=325.13 \mathrm{M}+1),(1)(\mathrm{m} / \mathrm{z}=451.05 \mathrm{M}+1),(2)(\mathrm{m} / \mathrm{z}=$ 485.05 M+1) and (3) $(\mathrm{m} / \mathrm{z}=777.95 \mathrm{M}+1)$.

The best indication for the phthalocyanine systems is their UV-visible spectra in solutions. The phthalocyanines exhibit typical electronic spectra with two strong absorbtion regions, one of them is in the UV region at about $300-400 \mathrm{~nm}$ (B band) and the other one is in the visible region at $600-700 \mathrm{~nm}(\mathrm{Q}$ band). The $\mathrm{Q}$ band was attributed to $\pi \rightarrow \pi^{*}$ transitions from the highest occupied molecular orbital (HOMO) to the lowest unoccupied molecular orbital (LUMO) of the phthalocyanine ring. The other bands (B) in the UV region are observed due to the transitions from the deeper $\pi$ levels to the $\mathrm{LUMO}^{25}$. The newly synthesized metal phthalocyanines (1a, 2a and 3a) showed typical electronic spectra with two strong absorption regions, one of them in UV region at about $267 \mathrm{~nm}$ and 343 $\mathrm{nm}$ ( $\mathrm{B}$ band) and the other in the visible region at about 682 $\mathrm{nm}$ (Q band) in DMSO, respectively. The UV-visible spectra of newly synthesized phthalocyanines can be seen in Figs. 3-5.

Aggregation properties: Electronic spectral properties of phthalocyanines are central to their chemical and electrical properties and are governed by the $18 \pi$ system of the most

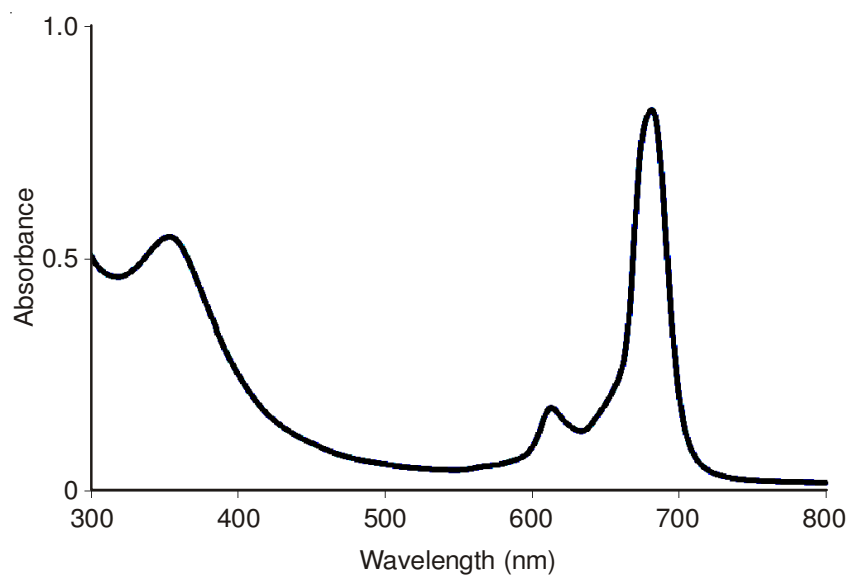

Fig. 3. UV/visible spectra of phthalocyanine (1a) in DMSO

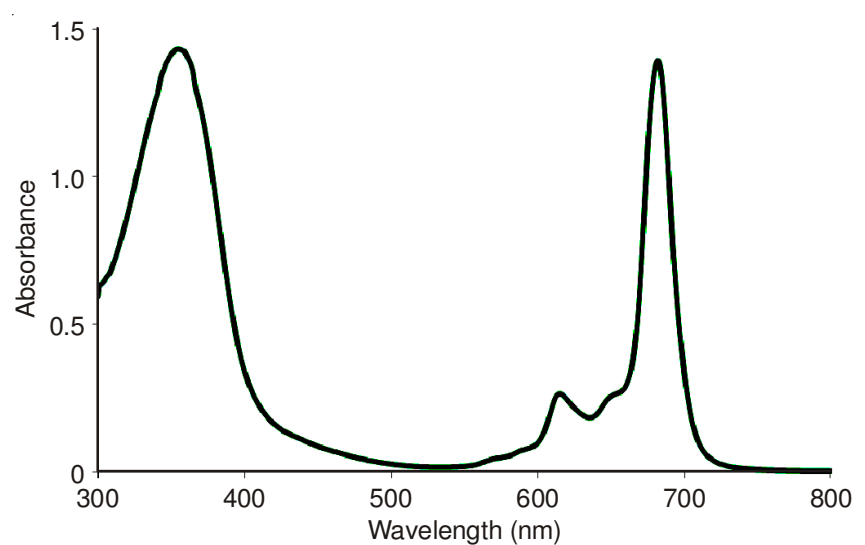

Fig. 4. UV/visible spectra of phthalocyanine (2a) in $\mathrm{CHCl}_{3}$

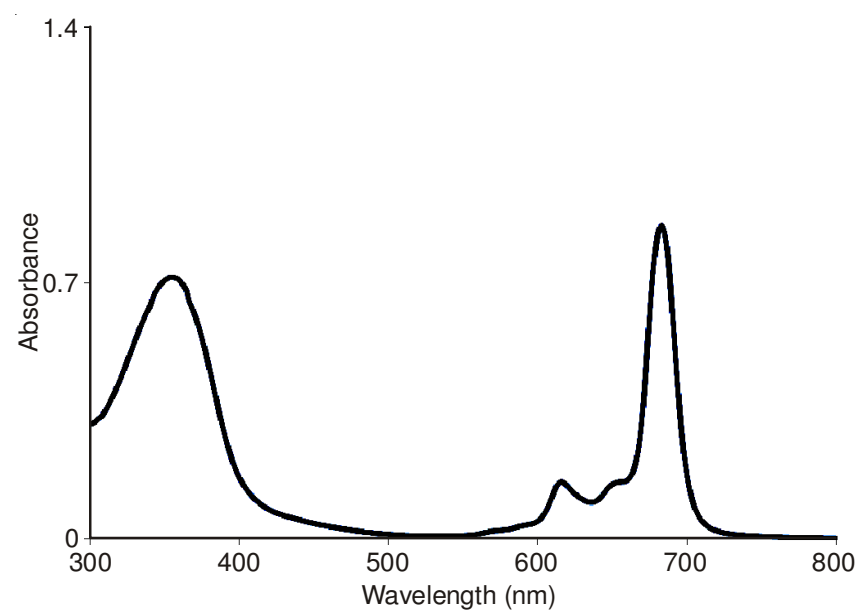

Fig. 5. UV/visible spectra of phthalocyanine (3a) in $\mathrm{CHCl}_{3}$

inner 16-membered ring. Electronic spectra consist of an intense absorption band in the visible region around 600-700 $\mathrm{nm}$ (Q band) and a generally weak band in the UV region at about 300-350 nm (Soret or B-band). The colour of the phthalocyanine molecules is a consequence of the Q-band. The UVvisible spectra of the phthalocyanines were highly solventand concentration dependent. At high concentrations or with solvents of high protic character, aggregates are formed. Moreover, the presence of an electron-donating group or bulky substituents on the periphery causes a bathochromic shift on Q-bands or the hindrance of aggregations, respectively ${ }^{26}$. Aggregation is usually depicted as a coplanar association and is dependent on the concentration, nature of the solvent, nature of the substituents, complexed metal ions and temperature ${ }^{27,28}$. In the aggregated state, the electronic structure of the complexed phthalocyanine ring is perturbed resulting in alteration of the ground and excited state electronic structures ${ }^{29,30}$.

In this study, the aggregation behaviour of the zinc(II) phtahlocyanines (1a, 2a and 3a) were investigated at different concentrations in DMF (for 1d) and $\mathrm{CHCl}_{3}$ (for $\mathbf{2 d}$, 3d). (Fig. 6 for complex 1a, Fig. 7 for complex 2a and Fig. 8 for complex 3a). As the concentration was increased, the intensity of the absorption of the $\mathrm{Q}$ band also increased and there were no new bands due to the aggregated species ${ }^{31}$. So, these complexes exhibited a monomeric form (i.e. no new blue-shifted band due to aggregation) as deduced from the recorded absorbtion spectra in different concentrations. The zinc(II) phtahlocyanines 


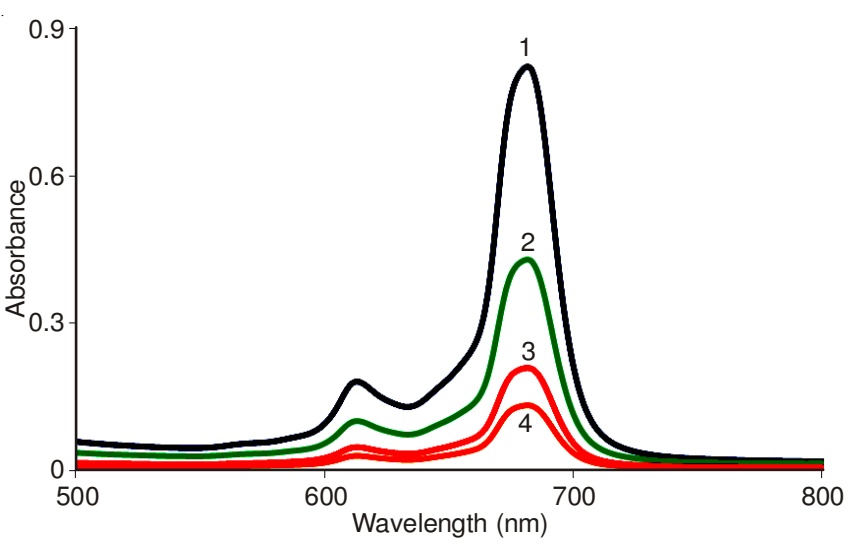

Fig. 6. UV/visible spectra of phthalocyanine different concentration in DMSO (1a)

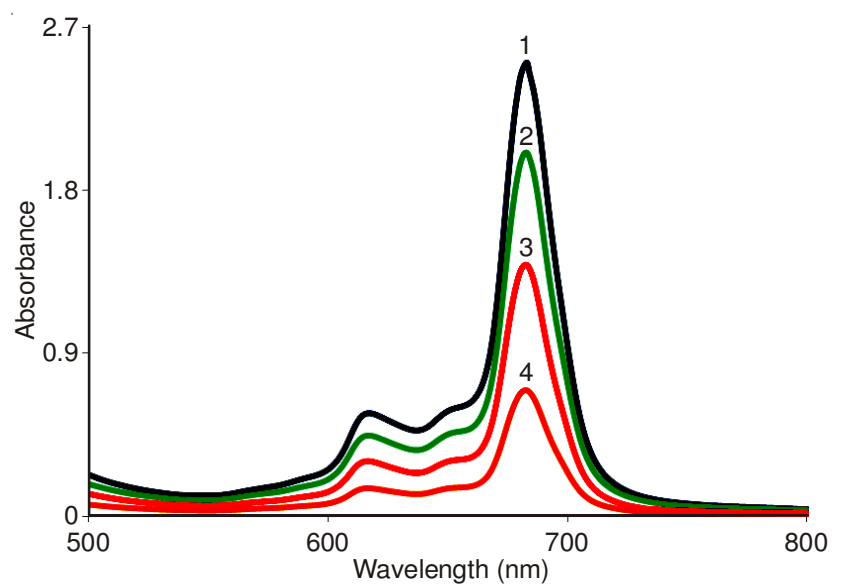

Fig. 7. UV/visible spectra of phthalocyanine different concentration in $\operatorname{DMSO}(\mathbf{2 a})$

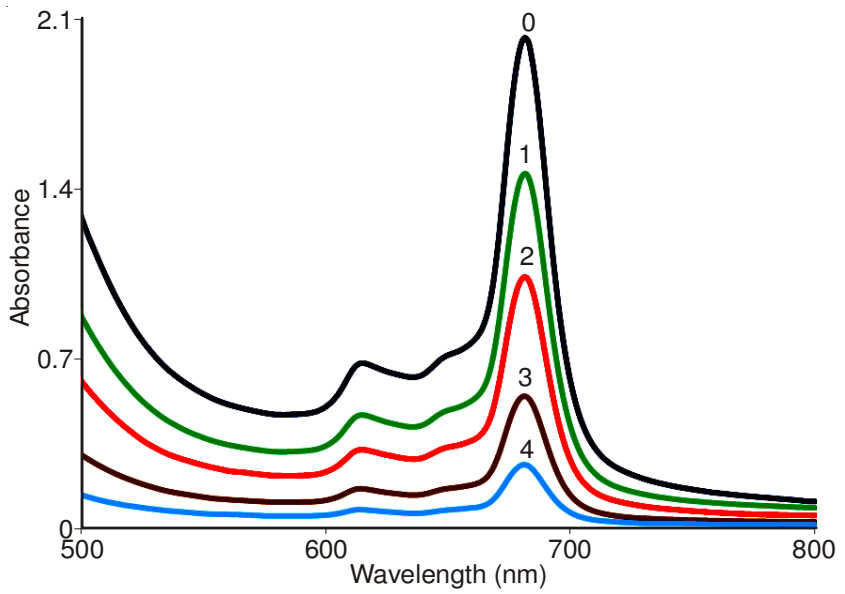

Fig. 8. UV/visible spectra of phthalocyanine different concentration in DMSO (3a)

(1a, 2a and 3a) did not show high aggregation in DMF and chloroform solvent. This may be related to be bulky groups like halogen as substituent.

In the electronic spectra of the metallo-phthalocyanines 1a-3a intense Q absorption bands were observed at 681, 682, $683 \mathrm{~nm}$, respectively, with weaker absorptions at 614, 615,
$616 \mathrm{~nm}$, respectively. Weaker absorptions on the higher energy side of the $\mathrm{Q}$ bands are generally observed in the case of metallo-phthalocyanines, indicating the presence of aggregated species together with the monomeric ones which are essentially responsible for the intense absorption occurring in the main $\mathrm{Q}$ bands ${ }^{32}$.

\section{Conclusion}

Preparation of some phthalocyanines $(\mathrm{Zn})$ substituted with azo compound has been achieved using microwave irradiation. Absorption and aggregations properties were investigated. The zinc(II) phtahlocyanines did not show high aggregation in solutions. This may be related to be bulky groups like halogen as substituent.

\section{REFERENCES}

1. H. Eichhorn, J. Porphyr. Phthalocyanines, 88, (2000).

2. C.C Leznoff and A.B.P Lever, Phthalocyanines: Properties and Applications, VCH, New York Vol. 1, (1993); Vols. 2 and 3; vol. 4) (1989).

3. M. Hanack and M. Lang, Adv Mater., 6, 819 (1994).

4. C.S. Frampton, J.M. O' Conner, J.I.M. Peterson and J. Silver, Displays., 9. 174 (1988)

5. J.H. Zagal, Coord. Chem. Rev., 119, 89 (1992).

6. A.C.H. Ng, X.-Y. Li and D.K.P. Ng, Macromolecules, 32, 5292 (1999).

7. H. Ali and J.E. van Lier, Chem. Rev., 99, 2379 (1999).

8. M.C. Derosa and R.J. Crutchely, Coord. Chem. Rev., 233, 351 (2002).

9. P. Tau and T. Nyokong. Inorg. Chim. Acta, 360, 2615 (2007).

10. N.S. Lebedeva, O.V. Petrova, A.I. Vyugin, V.E. Maizlish and G.P. Shaposhnikov. Thermochim. Acta, 417, 127 (2004).

11. A. Loupy, Microwaves in Organic Synthesis, Wiley-VCH, Weinheim (2002).

12. S.J. Haswell and H.M. Kingston, Microwave-Enhanced Chemistry: Fundamenals, Sample Preparation and Application, Americal Chemical Society, Washington, DC (1997).

13. W.H. Sutton, Am. Ceram. Soc. Bull., 68, 376 (1989).

14. S.S. Park, E.H. Hwang, B.C. Kim and H.C. Park, H.C Park. J. Am. Ceram. Soc., 83, 1341 (2000)

15. C. Kantar, N. Akdemir, E. Agar, N. Ocak and S. Sasmaz, Dyes Pigments, 76, 7 (2008).

16. B. Kahveci, S. Sasmaz, M. Ozil, C. Kantar, B. Kosar and O. Büyükgüngör, Turk. J. Chem., 30, 681 (2006).

17. M. Ozil, E. Agar, S. Sasmaz, B. Kahveci, N. Akdemir and I.E Gümrukcuoglu, Dyes Pigments, , 75, 732 (2007).

18. C. Kantar, F. Mert and S. Sasmaz, J. Organomet. Chem., 696, 3006 (2011).

19. J.G. Young and W.J. Onyebuagu, J. Organomet. Chem., 55, 2155 (1990).

20. D. Wöhrle, M. Eskes, K. Shigehara and A. Yamada, Synthesis, 194 (1993).

21. E. Besson, A. Mehdi, V. Matsura, Y. Guari, C. Reye and R.J.P. Corriu, Chem.Commun., 1775 (2005).

22. A. Gürek and O. Bekaroglu, J. Porphyr. Phthalocyanines, 1, 67 (1997).

23. A. Gürek and O. Bekaroglu, J. Porphyr. Phthalocyanines, 1, 227 (1997).

24. M. Kandaz, M.N.U. Yarasir, A. Koca and O. Bekaroglu, Polyhedron, 21, 255 (2002).

25. S. Merey and O. Bekaroglu, J. Chem. Soc. Dalton Trans., 4503 (1999).

26. A.A. Esenpinar, A.R. Ozkaya and M. Bulut, Polyhedron, 28, 3129 (2009).

27. M. Durmus, M.M. Ayhan, A.G. Gürek and V. Ahsen, Dyes Pigments, 77, 570 (2008).

28. H. Engelkamp and R.J.M. Nolte, J. Porphyr. Phthalocyanines, 4, 454 (2000).

29. D.D. Dominguez, A.W. Snow, J.S. Shirk and R.G.S. Pong, J. Porphyr. Phthalocyanines, 5, 582 (2001).

30. S. Makhseed and J. Samuel, Dyes Pigments, 82, 1 (2009).

31. A.W. Snow and N.L. Jarvis, J. Am. Chem. Soc., 106, 4706 (1984).

32. F. Yilmaz, D. Atilla and V. Ahsen, Polyhedron, 23, 1931 (2004). 